\title{
Carbon monoxide poisoning in narghile (water pipe) tobacco smokers
}

\author{
Giovanna La Fauci, MD*; Giora Weiser, MD; Ivan P. Steiner, MD; Itai Shavit, $\mathrm{MD}^{\dagger}$
}

\section{ABSTRACT}

Narghile (water pipe, hookah, shisha, goza, hubble bubble, argeela) is a traditional method of tobacco use. In recent years, its use has increased worldwide, especially among young people. Narghile smoking, compared to cigarette smoking, can result in more smoke exposure and greater levels of carbon monoxide (CO). We present an acutely confused adolescent patient who had $\mathrm{CO}$ poisoning after narghile tobacco smoking. She presented with syncope and a carboxyhemoglobin level of $24 \%$ and was treated with hyperbaric oxygen. Five additional cases of $\mathrm{CO}$ poisoning after narghile smoking were identified during a literature search, with carboxyhemoglobin levels of 20 to $30 \%$. Each patient was treated with oxygen supplementation and did well clinically. In light of the increasing popularity of narghile smoking, young patients presenting with unexplained confusion or nonspecific neurologic symptoms should be asked specifically about this exposure, followed by carboxyhemoglobin measurement.

\section{Keywords: carbon monoxide, intoxication, narghile}

Carbon monoxide (CO) poisoning is one of the leading causes of death in both adults and children worldwide. ${ }^{1-3} \mathrm{CO}$ intoxication can be notoriously nonspecific in its initial presentation to the emergency department (ED), leading to a delay in diagnosis and treatment. Typical peak carboxyhemoglobin $(\mathrm{CO}-\mathrm{Hb})$ concentrations in narghile smokers are greater $(10.1 \%)$ than in cigarette smokers $(6.5 \%)$ or nonsmokers $(1.6 \%)$, and a single narghile smoking session results in substantially more smoke and CO exposure compared to cigarette smoking, despite similar plasma nicotine concentrations. A linear relationship exists between smoking intensity and $\mathrm{CO}$ concentration. ${ }^{4-6}$

\section{CASE REPORT}

A 16-year-old acutely confused female was brought by the emergency medical service to the pediatric ED. According to her friend, this previously healthy patient smoked narghile for approximately 3 hours while socializing with friends at a local beach. While smoking, she suddenly complained of headache, dizziness, nausea, and weakness, which were followed by syncope. It was also reported that she spent many hours in the sun without proper hydration. The patient denied using alcohol or illicit drugs.

On ED admission, the patient was confused and uncooperative and had slurred speech. The Glasgow Coma Scale (GCS) score was calculated as 12 (motor, 5; verbal, 3; eyes, 4). Vital signs were normal: pulse 86 beats/min, blood pressure 104/89 $\mathrm{mm} \mathrm{Hg}$, oxygen saturation by pulse oximetry $99 \%$ on room air, and oral temperature $37.3^{\circ} \mathrm{C}\left(99.1^{\circ} \mathrm{F}\right)$. Her capillary blood glucose was $5.1 \mathrm{mmol} / \mathrm{L}$. Apart from the confusion, the rest of the examination was normal. In particular, no signs of dehydration were found; she had moist mucous membranes, normal skin turgor, and normal capillary refill.

The laboratory workup included complete blood count, electrolytes, blood urea nitrogen, and creatinine, which were normal, and blood gas analysis, which revealed $\mathrm{pH} 7.46$, bicarbonate $21.5 \mathrm{mmol} / \mathrm{L}$, base excess -0.9 , lactate $2.8 \mathrm{mmol} / \mathrm{L}$, and $\mathrm{CO}-\mathrm{Hb}$ of $24 \%$

From the *Pediatric Department, Arcispedale S. Anna Hospital, Ferrara University, Ferrara, Italy; †Emergency Department, Meyer Children's Hospital, Rambam Health Care Campus, Haifa, Israel; and FFaculty of Medicine and Dentistry, University of Alberta, Edmonton, AB.

Correspondence to: Dr. Itai Shavit, Emergency Department, Meyer Children's Hospital, Rambam Health Care Campus, Haifa, Israel, 31096; i_shavit@rambam.health.gov.il.

Submitted November 23, 2010; Revised March 29, 2011; Accepted April 2, 2011.

This article has been peer reviewed.

(c) Canadian Association of Emergency Physicians

CJEM 2012;14(1):57-59

DOI 10.2310/8000.2011.110431

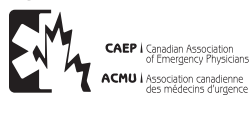


(normal 0-1.5\%). The electrocardiogram was normal, without arrhythmia or ischemia. The patient was initially treated with $100 \%$ oxygen via a nonrebreather mask, and marked improvement was noticed prior to receiving the laboratory results. She became more cooperative, and her GCS score returned to 15 .

Given that the patient had syncope and transient neurologic symptoms, a decision was made to treat the patient with hyperbaric oxygen (HBO; 2.8 atmospheres for 2 hours). Following this treatment, she remained asymptomatic until her discharge the following day.

We performed an online literature search of relevant articles published from 1966 to 2010 in PubMed using several keywords: narghile, water pipe, hookah, shisha, goza, hubble bubble, smoking, poisoning, intoxication, carbon monoxide, and CO. The Internet search engine Google Scholar was also used to identify relevant articles published in reputable books, journals, and websites.

We identified five previous reports of CO poisoning related to narghile tobacco smoking; none were fatal. ${ }^{7-11}$ The first case was reported in Saudi Arabia in 2000.7 Since then, four more cases were reported in France, ${ }^{8}$ Singapore, ${ }^{9}$ and Turkey. ${ }^{10,11}$ Our case is the first report of this entity in an adolescent (Table 1).

\section{DISCUSSION}

Narghile (water pipe, hookah, shisha, goza, hubble bubble, argeela) is a traditional method of smoking tobacco in the eastern Mediterranean region and countries of the Arabian Peninsula (Figure 1). In recent years, its use has increased worldwide, especially among young people. ${ }^{1-3}$ Studies that investigated the prevalence of narghile smoking among university students in the eastern Mediterranean region reported that narghile smoking is the most socially acceptable form of tobacco use. ${ }^{1-3}$ In Syria and Jordan, narghile smoking is more prevalent among male university students (62.6\% and $61.9 \%$, respectively). In Israel, a national survey of approximately 6,000 male and female high school students found that $37.7 \%$ had smoked narghile and that the rates were higher among Jewish (39.5\%) than among Arab (30.5\%) students. ${ }^{1,3}$ In France and other European nations, there has been an upsurge of narghile use in the past several years. ${ }^{1}$

Many young smokers believe that narghile smoking is less harmful than cigarettes, perhaps because of its attractive smell and taste. These youth believe it to be safe despite public education about the detrimental health effects of narghile smoking. ${ }^{1-5}$

Narghile smokers can smoke for several hours at a time and inhale more deeply because of the less irritating nature of the moisturized smoke. Contrary to popular opinion, the water in the narghile filters only a small portion of the noxious substances. Narghile smokers absorb higher concentrations of CO than cigarette smokers because of the larger volumes inhaled with each puff and the longer duration of smoking session. Furthermore, CO concentrations in the inhaled vapours are higher because of the charcoal used to burn the narghile tobacco. ${ }^{1}$

In all the reported cases identified, $\mathrm{CO}-\mathrm{Hb}$ levels at presentation to hospital ranged from 20 to $30 \%$. These patients were treated with oxygen supplementation and did well clinically. None of the previously reported cases were treated with HBO (see Table 1). Although the use of $\mathrm{HBO}$ in $\mathrm{CO}$ poisoning is controversial and depends on both clinical variables and $\mathrm{CO}-\mathrm{Hb}$ levels, patients with loss of consciousness or altered mental status are generally considered candidates for this therapy. ${ }^{12}$ Additionally, HBO therapy is believed to decrease neurologic injury that may occur after a latent period of 2 to 21 days ("delayed neurologic sequelae") after mild to moderate $\mathrm{CO}$ poisoning. ${ }^{12}$ Our decision to treat with $\mathrm{HBO}$ was based on the patient's loss of consciousness and transient neurologic symptoms.

\begin{tabular}{|lcccc|}
\hline \multicolumn{4}{|c|}{ Table 1. Summary of reported cases of carbon monoxide poisoning related to narghile smoking } \\
\hline & Patient's age $(\mathrm{yr})$ & $\begin{array}{c}\text { Patient's } \\
\text { gender }\end{array}$ & $\begin{array}{c}\text { Carboxyhemoglobin } \\
\text { level }(\%)\end{array}$ & $\begin{array}{c}\text { Treatment with } \\
\text { hyperbaric oxygen }\end{array}$ \\
\hline Al-Moamary et al ${ }^{7}$ & Not reported & Not reported & 30 & Not reported \\
Levant et al ${ }^{8}$ & Not reported & Not reported & 20.8 & Not reported \\
Lim et al ${ }^{9}$ & 19 & Male & 27.8 & No \\
Uyanik et al ${ }^{10}$ & 25 & Male & 28.7 & No \\
Cavus et al ${ }^{11}$ & 25 & Male & 31.1 & No \\
Our patient & 16 & Female & 24.0 & Yes \\
\hline
\end{tabular}




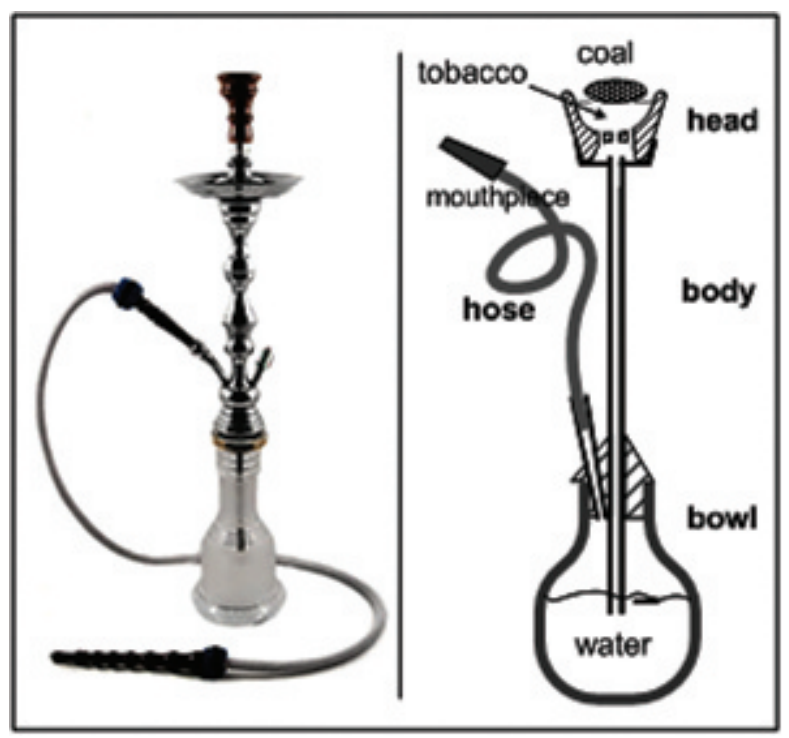

Figure 1. Water-pipe apparatus for Narghile smoking.

\section{CONCLUSION}

The ability to diagnose and thus treat $\mathrm{CO}$ poisoning is always based on an increased index of suspicion. In light of the increased use of narghile smoking, young patients presenting with otherwise unexplained confusion or nonspecific neurologic symptoms should be specifically asked about its use.

Competing interest: None declared.

\section{REFERENCES}

1. Knishkowy B, Amitai Y. Water-pipe (narghile) smoking: an emerging health risk behavior. Pediatrics 2005;116:e113-9, doi:10.1542/peds.2004-2173.
2. Chaouachi K. Hookah (shisha, narghile) smoking and environmental tobacco smoke (ETS). A critical review of the relevant literature and the public health consequences. Int 7 Environ Res Public Health 2009;6:798-843, doi:10.3390/ ijerph6020798.

3. Dar-Odeh NS, Bakri FG, Al-Omiri MK, et al. Narghile (water pipe) smoking among university students in Jordan: prevalence, pattern and beliefs. Harm Reduct 7 2010;7:10, doi:10.1186/1477-7517-7-10.

4. Primack BA, Walsh M, Bryce C, et al. Waterpipe tobacco smoking among middle and high school students in Arizona. Pediatrics 2009;123:e282-8, doi:10.1542/peds.2008-1663.

5. Eissenberg T, Shihadeh A. Waterpipe tobacco and cigarette smoking direct comparison of toxicant exposure. Am $\mathcal{F}$ Prev Med 2009;37:518-23, doi:10.1016/j.amepre.2009.07.014.

6. Zahran FM, Ardawi MSM, al-Fayez S. Carboxyhaemoglobin concentrations in smokers of sheesha and cigarettes in Saudi Arabia. BMF 1985;291:1768-70, doi:10.1136/bmj.291. 6511.1768-a.

7. Al-Moamary MS, Al-Shammary AS, Al-Shimemeri AA, et al. Complications of carbon monoxide poisoning. Saudi Med 7 2000;21:361-3.

8. Levant A, Cabot C, Genestal M, et al. [Acute CO poisoning after smoking narghile]. Presented at the 22e Journée de Tabacologie; 2006; Paris.

9. Lim BL, Lim GH, Seow E. Case of carbon monoxide poisoning after smoking shisha. Int 7 Emerg Med 2009;2:1212, doi:10.1007/s12245-009-0097-8.

10. Uyanik B, Arslan ED, Akay H, et al. Narghile (hookah) smoking and carboxyhemoglobin levels. 7 Emerg Med 2011; 40:679.

11. Cavus UY, Rehber ZH, Ozeke O, et al. Carbon monoxide poisoning associated with narghile use. Emerg Med 7 2010; 27:406, doi:10.1136/emj.2009.077214.

12. Wolf SJ, Lavonas EJ, Sloan EP, et al. American College of Emergency Physicians. Clinical policy: critical issues in the management of adult patients presenting to the emergency department with acute carbon monoxide poisoning. Ann Emerg Med 2008;51:138-52, doi:10.1016/j.annemergmed. 2007.10.012. 